\title{
Integration of CMIS and MS Project in Construction Schedule Control
}

\author{
Hsi-Chi Yang, Yan-Chyuan Shiau, Ging-Jae Huang, Chih-Kun Chu and Tsung-Pin Tsai
}

\begin{abstract}
The Application of IT is not as popular as other areas at Construction Industry in Taiwan. Since IT can help enterprises to integrate most complex information, we can make big progress in cost, quality and service. Construction Industry has to integrate surveying, planning, design, structural design, shop drawing, contracting, valuation, and so on, we need a good tool help us to handle those complicate tasks to effectively administrate construction projects. In this research, we use ER Modeling and Window programming environment to develop Basic Database System, Construction Site Record System, Daily Report System, and Integrate between CMIS and MS Project. Through the help of these modules, we can record the site information such as labor, equipment and material. This information will be automatically integrated to CMIS system to generate and update project schedule control information. All site information will be transferred to headquarter so administrators can control real situation for the enterprise. Combined with MS Project, we can update and show project schedule so project managers can exactly control the schedule of the project.
\end{abstract}

Index Terms-Estimate, MS Project, Schedule Control, Site Records.

\section{ORIGIN AND OBJECTIVE}

A t present, the unformatted level of the domestic construction industry is obviously lower than other domestic industries; yet due to active development of information technology over recent years, application of computers is already popular. The construction industry must follow this trend and thus unformatted construction has already been a very important issue to be discussed at present. Since participants in the team of construction management are extensive, the amount of operation procedure is heavy and each operation interlinks

This work was supported in part by the National Science Council, Executive Yuan, Taiwan under Grant NSC 92-2622-E-216-024-CC3.

Hsi-Chi Yang is with the Department of Construction Engineering, Chung-Hua University, Hsin-Chu, 300 Taiwan (E-mail: hcyangse @chu.edu.tw).

Yan-Chyuan Shiau is with the Department of Construction Engineering, Chung-Hua University, Hsin-Chu, 300 Taiwan (Tel: 886-3-5186689; Fax: 886-3-5378846; E-mail: ycshiau@ms22.hinet.net).

Ging-Jae Huang is the graduate student of the Institute of Construction Management, Chung-Hua University, Hsin-Chu, 300 Taiwan (E-mail: m9216008@chu.edu.tw)

Chih-Kun Chu is with the Excellent Instrument \& Engineering Co. Ltd., Tu-Chen, Taipei, 236 Taiwan (E-mail: jack@excellent.com.tw)

Tsung-Pin Tsai is with the Construction Section, Chu-Nan Town Hall, Miao-Li, Taiwan (E-mail: winnie.bears@msa.hinet.net) with each other; it is a matter very much worth of research on how to execute, connect and compile when the managing team is performing the operation procedure and relevant operation.

Facing such a vast project, the key to success was the schedule control. For the construction industry, if a penalty was applied for schedule delayed under the current state of low profit margin, the profit might be gone, which caused financial loss. Therefore, the project personnel must be very careful during managing control of the schedule. Upon overall control of project schedule, the information needed was very trivial and complicated, where the information depending on manual writing consumes lots of time, mistakes occurred easily and the search of information was difficult. Because of this, many packaged systems of construction management were available in the market, but many were products completely developed domestically and most of them were packaging software technically cooperated with foreign technology to sell in the market. Since the price was expensive and the online threshold was high, which made it difficult to bring out the estimated effect. This has been the main factor of the impossibility to generally carry out electronic construction management.

In view of the above-mentioned current state, this research proposed development of the "Integrate CMIS and MS Project in Construction Schedule Control”. The calculated result of project preliminaries was saved in the system for future operation. In this way, a large amount of repetitive calculation and input could be saved; as well as prevent mistakes caused by human factors during calculation. During integration of the information system to combine with the MS Project for input of daily reports, this research could automatically renew the network. This has made the renewal of the network to be simple and convenient instead of the hassle in the past upon renewal of the network. With the analysis on the practical requirements of the project, the objective of this research was to complete the module of "Integrate CMIS and MS Project in Construction Schedule Control”. The previous construction management information system has been equipped with a basic database module, purchase \& contracting module and assessment \& costing module. The completion of the schedule control system in this program will expand the functionality. 


\section{FUnCTIONAL REQUIREMENT}

The whole system of "Integrate CMIS and MS Project in Construction Schedule Control" included the following items:

1). Establishing a structure of basic information for the system, the work items of database divided into major items, medium items and detail items.

2). Developing a program of budget system, which could automatically produce project budget.

3). Developing a program of purchasing \& contracting system, which could automatically select the sub-contractor and execute contracting works.

4). Developing a program of budget review system, which could send out warning message for work item that exceeded the budget. (the above was the progress of 2001)

5). Developing a daily report system for the site to record daily work items, quantity and application of resources such as manpower, equipment and material.

6). Developing a managing system for costing \& payment application, which automatically transfers the completed items and quantity of the present period from the daily report system for the site.

7). Developing a managing system of design change to record work items and quantity of each design change of the project.

8). Developing a managing system of project settlement, which controls work items actually completed, cost \& revenue and expense of each project (the above-mentioned item 5 to 8 were the progress of research in 2002).

9). Comparing with the MS Project and transfer to correspondent columns in MS Access; so that relevant time, personnel, equipment and material entered into the schedule module can be completely reflected onto the MS Project for schedule management.

10). Developing a healthier daily report of project, which not only records project items, quantity and application of resources such as manpower, equipment and material on site every day, but also automatically transfers manpower, equipment and material into the schedule control system for control of schedule.

11). Developing the schedule control system, which could clearly display schedule, starting the time, finishing time, amount spent of each operation item in the project; as well as convenient search on the condition of project items of the project (the above-mentioned items 9 to 11 were the research progress of this year).

\section{DisCUSSION ON RELEVANT RELATIONSHIPS BETWEEN MS PROJECT \& MS ACCESS}

The information integration system of construction management -schedule control module developed by this research needs MS Access as a platform of schedule transformation.
This allows transfer of information (manpower, equipment \& material) accessed by CMIS to MS Project for plotting of network. Therefore, this section would discuss the relationships between MS Project, MS Access and CMIS.

\section{A. Mutual Relationships of Database Transformation}

From investigation of this research, it was discovered that MS Access acted as the center of database transformation in combination with CMIS (Construction Management Information System) and MS Project (Fig 1). The database of CMIS transformed into MS Access via ODBC (Fig 2), where the MS Project was transferred directly into MS Access. The database of the two transferred between each other via MS Access.

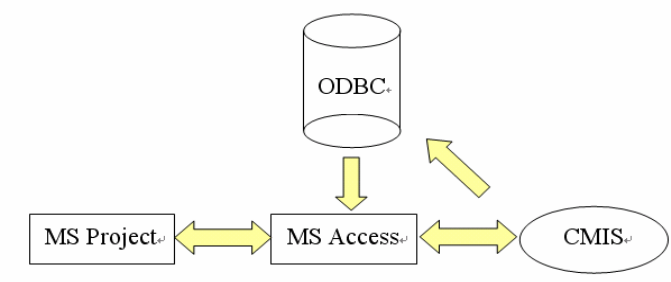

Fig 1. Relationships of information transformation

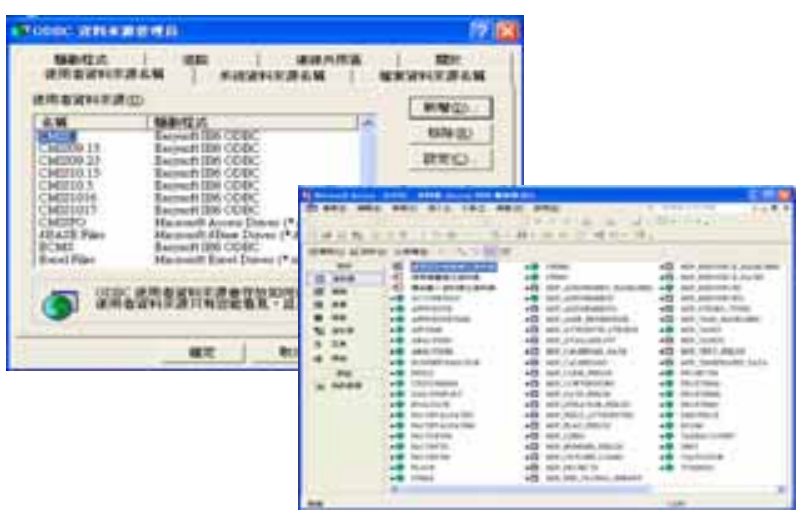

Fig 2. Information transfer via ODBC

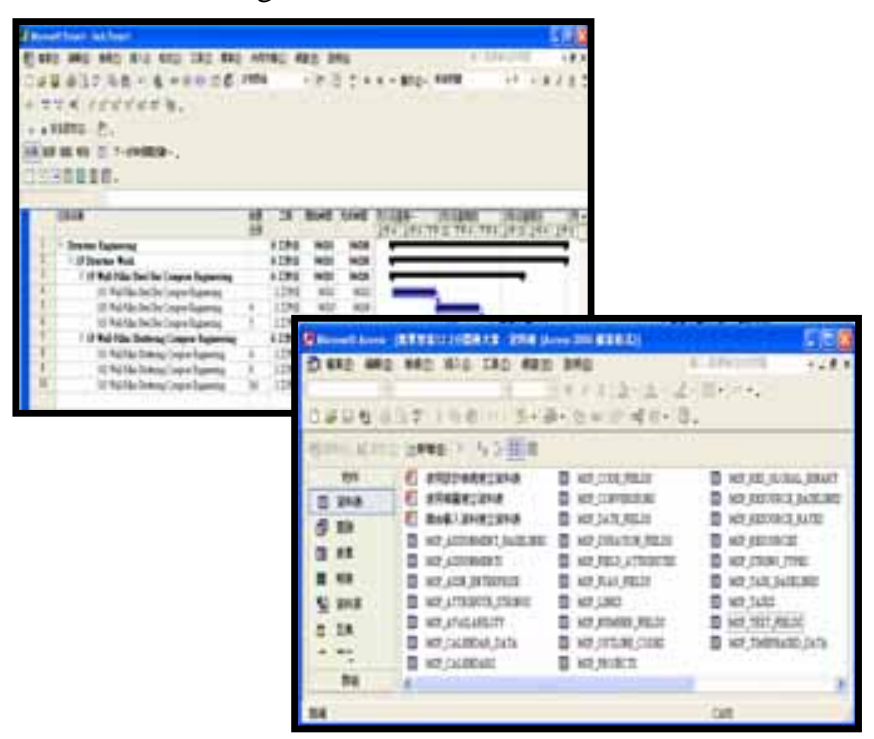

Fig 3. Project established in MS Project by this research 
The CMIS recorded manpower, equipment and materials of daily work, where calculation and transformation was made afterwards via MS Access with the date, quantity and amount of work to be done, as well as prompt reflection of project schedule.

This research used the schedule of a construction project for transforming MS Project into MS Access (Fig 3) ; which allows understanding on name \& property of information columns. The property of the database constructed by CMIS needed to be consistent with MS Project, otherwise information entered from CMIS would not be able to transfer to the MS Project successfully and show the project schedule.

Investigation of this research discovered that when information of the MS Project was transferred into MS Access, the name of the column was mission, resource and work distribution (Table1, 2 and 3) separately. Therefore the CMIS developed in this research must also establish these columns for information transfer.

\section{B. Proportion of value verification from transferring MS Project into MS Access}

When this research used a schedule of a construction project for example of transferring an MS Project into MS Access, it was discovered that the value would be different. After an investigation from this research on mission, resource and work distribution, it was discovered that the value of project schedule, work duration and cost had a certain proportional change on the three major columns. In the mission column, the value of the work schedule would be 4800 times the original value in the MS Project; the value of work duration would be 60000 times the original value in MS Project and the value of cost would be 100 times the original value in the MS Project. These were shown as in the following table:

Table 1.

Correspondence of mission

\begin{tabular}{|l|l|c|}
\hline \multicolumn{3}{|c|}{ MS Project Task Correspond } \\
\hline \hline \multicolumn{1}{|c|}{ Database Column } & \multicolumn{1}{|c|}{ Column Name } & Data Type \\
\hline TASK_UID & Exclusive Identification Code & INTEGER \\
\hline TASK_IS_CRITICAL & CRITICAL:-1, NO CRITICAL:0 & SMALLINT \\
\hline TASK_EARLY_FINISH & EARLY FINISH Date & DATETIME \\
\hline TASK_LATE_START & LATE START Date & DATETIME \\
\hline TASK_DUR & Duration & INTEGER \\
\hline TASK_ACT_DUR & Act Duration & INTEGER \\
\hline TASK_REM_DUR & Remain Duration & INTEGER \\
\hline TASK_BASE_DUR & Comparable Base Duration & INTEGER \\
\hline TASK_START_DATE & START Date & DATETIME \\
\hline TASK_FINISH_DATE & FINISH Date & DATETIME \\
\hline TASK_ACT_START & Act START Date & DATETIME \\
\hline TASK_ACT_FINISH & Act FINISH Date & DATETIME \\
\hline TASK_BASE_START & Comparable Base START Date & DATETIME \\
\hline TASK_BASE_FINISH & Comparable Base FINISH Date & DATETIME \\
\hline TASK_REM_COST & Leftover COST & DOUBLE \\
\hline TASK_BASE_COST & Comparable Base COST & DOUBLE \\
\hline TASK_NAME & NAME & VARCHAR \\
\hline TASK_PHY_PCT_COMP Act Finish Percentage & SMALLINT \\
\hline
\end{tabular}

Table 2.

Correspondence of work distribution

\begin{tabular}{|l|l|l|}
\hline \multicolumn{3}{|c|}{ MS Project Assignment } \\
\hline \multicolumn{1}{|c|}{ Database Column } & \multicolumn{1}{|c|}{ Column Name } & Data Type \\
\hline \hline ASSN_ACT_START & Act Start Date & DATETIME \\
\hline \hline ASSN_ACT_FINISH & Act Finish Date & DATETIME \\
\hline ASSN_START_VAR & Start Date Variation & INTEGER \\
\hline ASSN_FINISH_VAR & Finish Date Variation & INTEGER \\
\hline ASSN_UID & Exclusive Identification Code & INTEGER \\
\hline ASSN_START_DATE & Start Date & DATETIME \\
\hline ASSN_FINISH_DATE & Finish Date & DATETIME \\
\hline ASSN_BASE_START & Comparable Base Start Date & DATETIME \\
\hline ASSN_BASE_FINISH & Comparable Base Finish Date & DATETIME \\
\hline ASSN_UNITS & Unit & DOUBLE \\
\hline ASSN_WORK & Work Duration & DOUBLE \\
\hline ASSN_ACT_WORK & Act Work Duration & DOUBLE \\
\hline ASSN_REM_WORK & Remain Work Duration & DOUBLE \\
\hline ASSN_BASE_WORK & Comparable Base Work Duration & DOUBLE \\
\hline ASSN_COST & Cost & DOUBLE \\
\hline ASSN_ACT_COST & Act Cost & DOUBLE \\
\hline ASSN_REM_COST & Remain Cost & DOUBLE \\
\hline
\end{tabular}

Table 3.

Resource correspondence

\begin{tabular}{|l|l|l|}
\hline \multicolumn{3}{|c|}{ MS Project Resource Correspond } \\
\hline \multicolumn{1}{|c|}{ Database Column } & \multicolumn{1}{|c|}{ Column Name } & Data Type \\
\hline RES_NUM_OBJECTS & Objects Number & TNTEGER \\
\hline RES_UID & Exclusive Identification Code & TNTEGER \\
\hline RES_D & Code & RNTEGER \\
\hline RES_IS_OVERALLOCATED & Over Assign & SMALLINT \\
\hline RES_CAN_LEVEL & Can or No Leveling o & SMALLINT \\
& Can:-1, No:0 & \\
\hline RES_ACCRUE_AT & Cost Add Up Way & SMALLINT \\
\hline RES_OVT_WORK & Overtime Work Duration & DOUBLE \\
\hline RES_REM_WORK & Remain Work Duration & DOUBLE \\
\hline RES_PEAK & Maximum Use & DOUBLE \\
\hline RES_REM_COST & Remain Cost & DOUBLE \\
\hline RES_MATERIAL_LABEL & Material Label & LONGCHAR \\
\hline
\end{tabular}

Table 4

Transformation of value change from Project to Access

\begin{tabular}{|l|c|c|c|}
\hline data sheet & $\begin{array}{c}\text { Work schedule } \\
\text { (day) }\end{array}$ & $\begin{array}{c}\text { Work duration } \\
\text { (hour) }\end{array}$ & $\begin{array}{c}\text { Cost } \\
\text { (dollar) }\end{array}$ \\
\hline Task & $\times 4,800$ & $\times 60,000$ & $\times 100$ \\
\hline Resource & & $\times 60,000$ & $\times 100$ \\
\hline Assignment & & $\times 1,000$ & $\times 100$ \\
\hline
\end{tabular}

Since there would be a change of the certain proportion from transformation of MS Project value into MS Access, thus transformation on the value of the work progress, work duration and cost must also follow the multiplication; so that correct transformation into the information value of the MS Project could be made. 


\section{Discussion of Database Structure}

\section{A. Structural Analysis of Database}

The structure of the database is the core of the system; once there is a mistake in the structure of the database or an inconsistency in the user's needs, the mistake will occur in the whole information flow and cause the output of unexpected information. Therefore, drafting a structure for the database that complies with the requirements of systematic functions was the key to the success of the project.

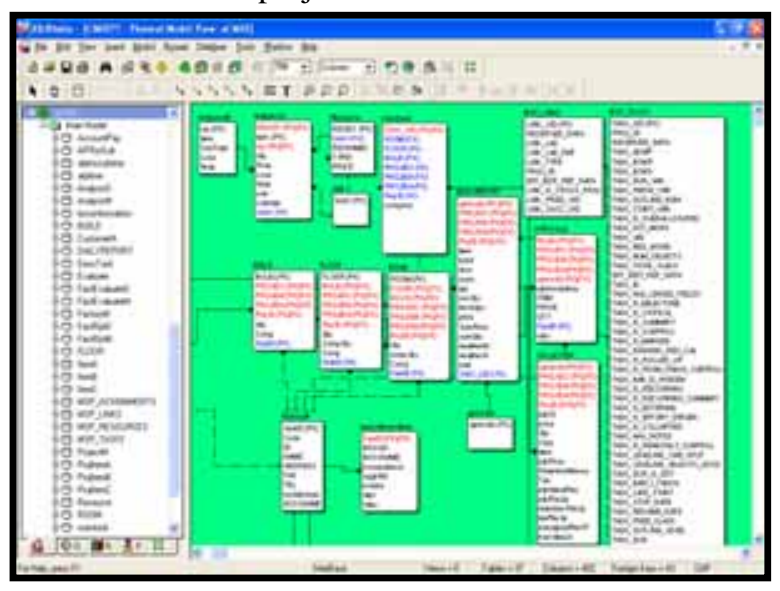

Fig 4 Structure of database relationships

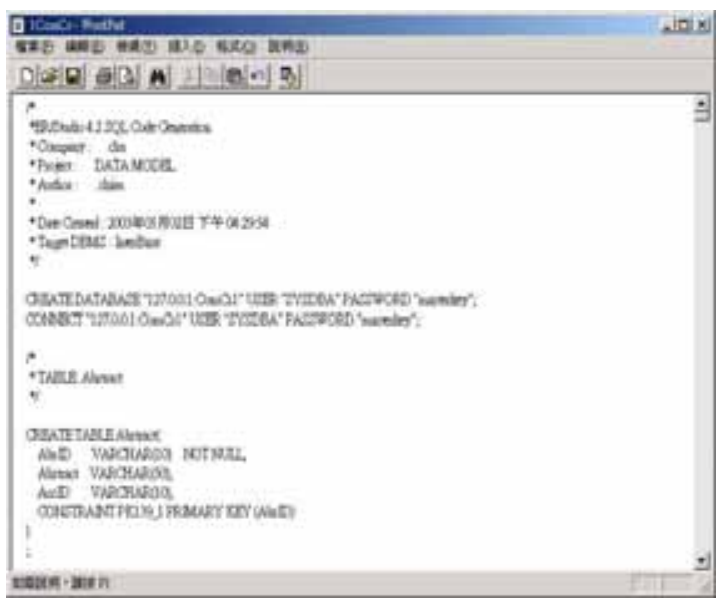

Fig 5 Script File in the database produced from ER/Studio

Along with advancing information technology, the database system has developed from the traditional "Relational Database” to an "Object-Oriented Database” (OODB). The OODB has become the mainstream of development of the database managing system 【1】. This research used the ER/Studio tool to build an ER Diagram, and then followed this model to plot the information procedure according to the user's requirement and built an E-R Model (Entity-Relationship Model). After definition of interactive relationships between columns and tables of each information sheet, the actual database was built, i.e. the database of actual relationships (as shown in Fig 4).

After building the ER/Model, the user may use tools provided by the software to transform the structure of the database into Script File ( as shown in Fig 5 ) readable by the normal database managing system. The Database Console is allowed to read the data sheet of the system, columns in each data table, property of each column, as well as the relationship between Primary Key and Foreign Key of each information sheet to build the database of system.

\section{B. Procedure of Daily Site Report}

The daily site report recorded work done and various matters that happened on the site every day. Since it was the center for site management, information collected from the site every day after compiling and analysis could derive a report on such matters as cost, schedule and quality 【2】.

Since the daily site report recorded things that happened on site every day and the matters to be recorded were numerous, this research classified matters recorded into project information, work personnel, personnel, equipment, material, quantity completed, work location, items of experiment, site journal and information of sheet filling.

The site record not only completed the daily site report; it must be used in cooperation with other sheets, e.g. weather records, work progress records, daily work hour records, equipment usage records, amount of rebar used, amount of concrete pouring, amount of formwork recorded and amount of landfill; which was the best to cooperate with work schedule and project network.

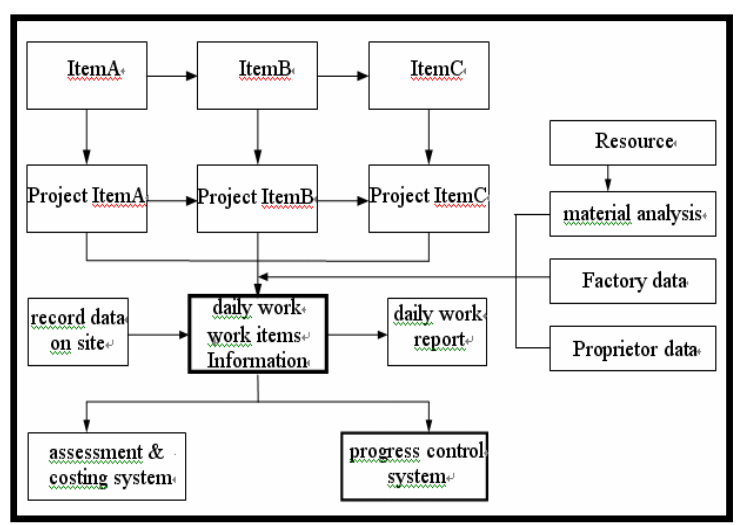

Fig 6 Structure of database for daily site report

\section{Procedure of Data Process on Daily Site Report}

Structure of database on daily site report made by this system 【3】 was shown in Fig 6. The system gathered work items from the basic database first and then transferred into work items of the project, which were integrated as information needed by the work items of the project via daily work system by recording things that happened on site and other relevant information (e.g. database of material analysis, company information). Work items were entered per work location via the structure of building, floor and rooms, where the daily site report was made after daily compiling. However, the data of personnel, equipment and material recorded every day could be automatically transferred to the assessment \& costing system and schedule 
control system via the system for convenience of control management.

\section{Procedure of Schedule Control}

From investigation of this research, it was discovered that the P3 and Project often used by the site at the current stage for schedule control made use of time. However, this could not properly reflect the project schedule while the schedule control system of this research used a monetary amount to control the project schedule.

Schedule control system developed in this research made use of the structure on building, floor and room system. In this way, schedule could be controlled accurately. Firstly, the operation of the system recorded personnel, equipment and material applied via daily site report, where the work location (building, floor, room) was then automatically transferred. Transformation was made by the system into the progress quantity afterwards, where database transformation was made via MS Access for timely reflection of project schedule.

\section{E. Structure of Building, Floor, and Room}

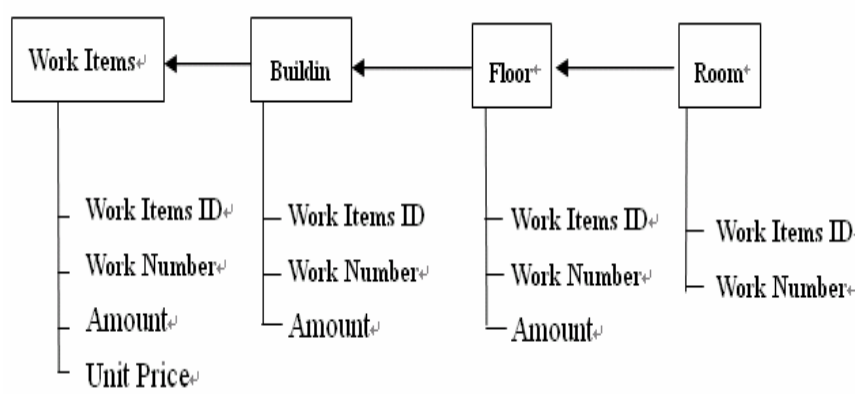

Fig 7 Structural illustrations of building, floor and room

This research added the structure of "building $\rightarrow$ floor $\rightarrow$ room” in the basic database (as shown in Fig 7) and integrated with the database of work items in the project. Information of work item in the system included work location; if there was a different rate due to different contractors, different parts of this structure could be used to simulate the condition of actual execution. This would allow for more appropriate information management on work items. Moreover, this structure could also be used on the aspect of schedule control for accurate calculation progress on each operation item. Formulas 1 to 3 were the relationships of quantity between "building, floor, room” with each work item 【4】; the work quantity of each room was compiled into quantity per floor; and then compiled the quantity per floor into quantity per building. Finally, these quantities would be summed up on quantities worked on work items.

$$
\begin{aligned}
& \mathrm{V}_{\text {floor }}=\sum_{i=1}^{n 1} V_{\text {room }} \\
& \mathrm{V}_{\text {building }}=\sum_{i=1}^{n 2} V_{\text {floor }}
\end{aligned}
$$

$$
\mathrm{V}_{\text {work items }}=\sum_{i=1}^{n 3} V_{\text {building }}
$$

Vroom : quantity worked per room; n1: rooms per floor

Vfloor : quantity worked per floor; n2: floors per building

Vbuilding : quantity worked per building; n3: no. of buildings for the project

$\mathrm{V}_{\text {work items: }}$ quantity that should have been worked for items in the project

\section{Planning Of the System Structure AND WORK CON- TENT}

This research completed the basic database, budget system, purchasing \& contracting system and fund assessment system with continuance of "establishment of construction information integration system (I) with object-orientated and visualized simulation”; as well as daily site report system, assessment-costing-payment application system, design change system and project settlement system with establishment of construction information integration system (II) with object-orientated and visualized simulation”.

However, this research will expand the functions of the daily site report, which may automatically transform the data of people, equipment and material into the quantity of progress; as well as further develop the schedule control module.

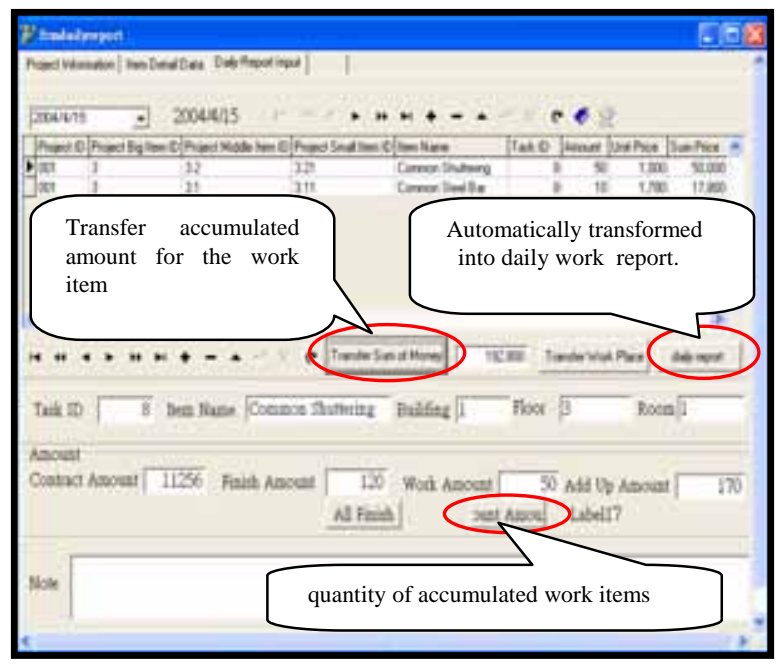

Fig 8 Entry of daily site report

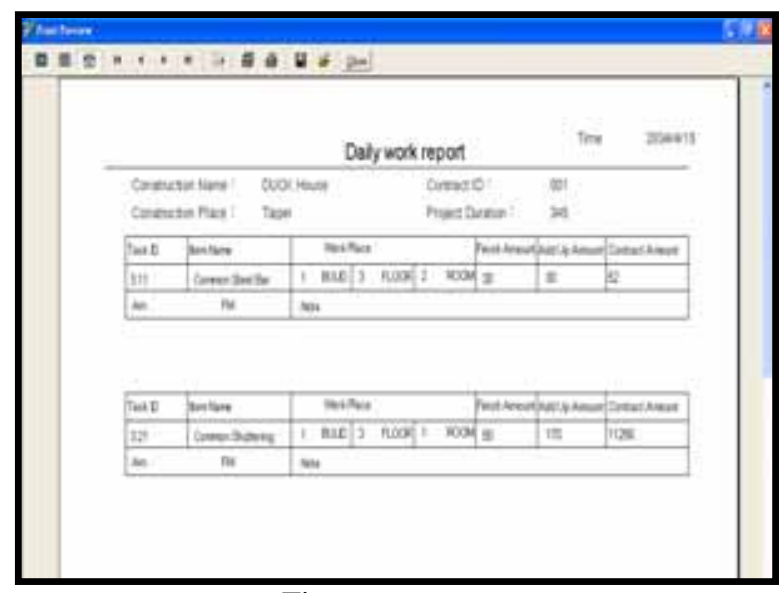

Fig 9 Daily site report 


\section{A. Daily Site Report System}

The daily site report system developed from this research could clearly record items, quantities and contracting quantity of work items with automatic display every day; as well as automatically transferring accumulated amount of work item for each operation into the schedule control system (Fig 8) . The system can even print the daily site report (Fig 9) , hence the performance was very powerful.

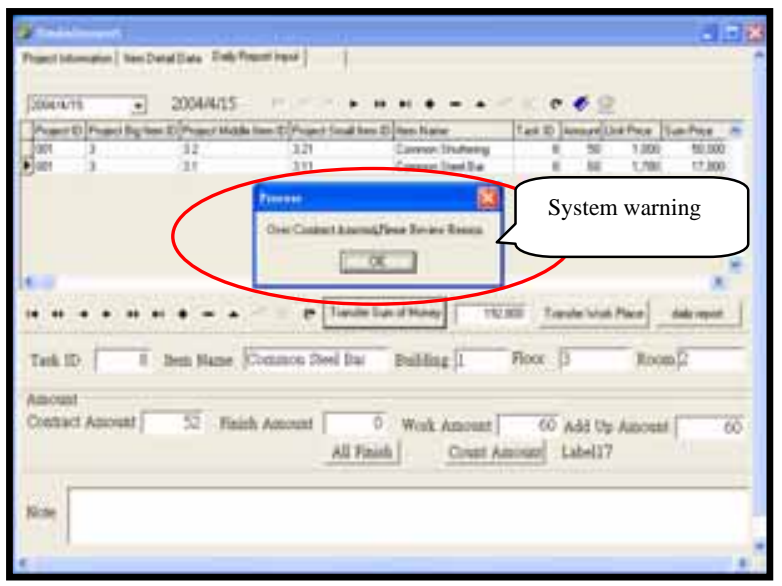

Fig 10 System warning

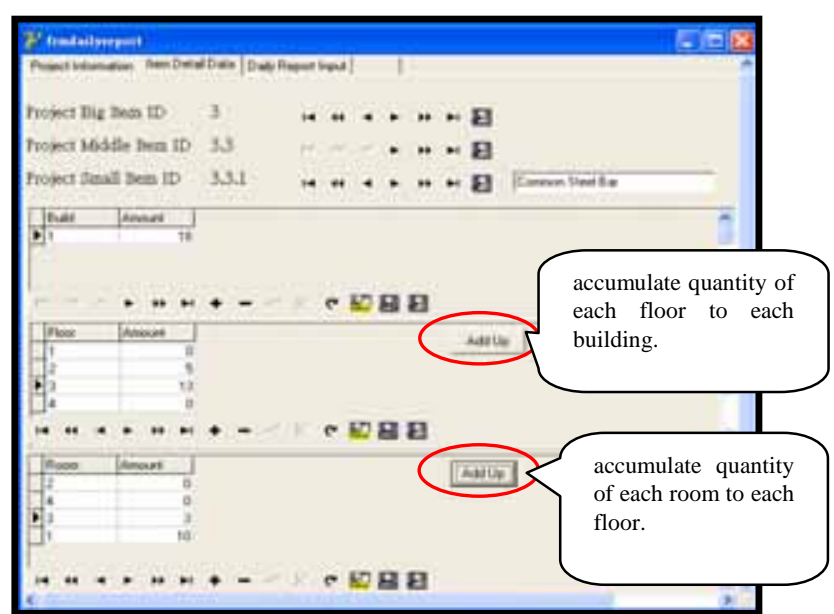

Fig 11 Work location and accumulated quantity of each work item

During entry of the daily site report, if the accumulated quantity of work items were more than the contracting quantity, the system would display the warning message (Fig 10) and remind the engineer to review.

However, the name of work item, quantity and weather conditions entered into the daily site report could also be made with input on location of such work item (building, floor, room). From the system, accumulating action (Fig 11) could be made, where the work location and accumulated quantity of each work item can be known accordingly.

\section{B. Schedule Control System}

From monetary amount of each item in the daily site report, schedule control system developed in this research automati- cally could calculate, transfer and reveal the result on such schedule control system (Fig 12). Whether it was the actual starting time, monetary amount of work, percentage of completion and actual finishing time of each operation item, calculation could be made automatically and displayed. If this schedule control system is to be combined with the MS Project and display the schedule network, data of this system must then be changed according to the proportion of transformation into the MS Project; so that the schedule network of MS Project can be displayed with no mistake.

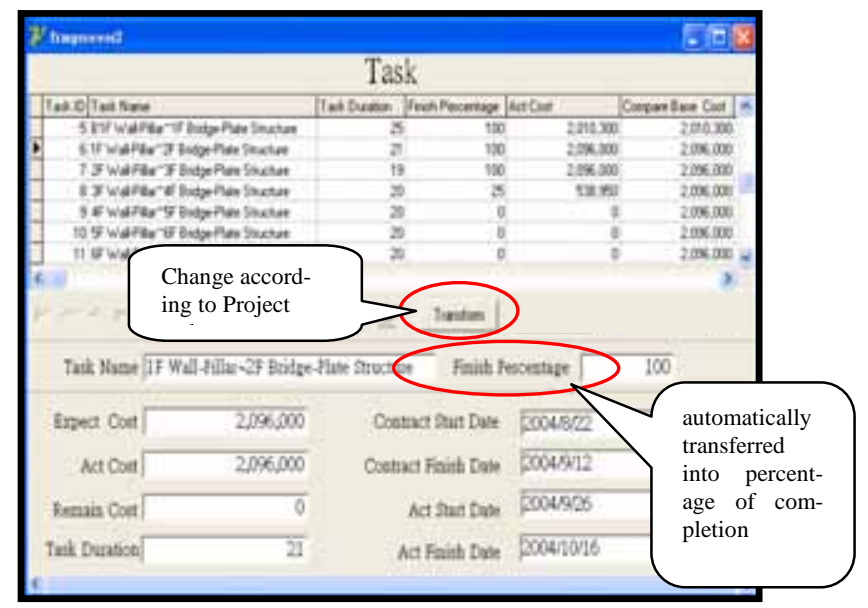

Fig 12 Main screen of schedule control system

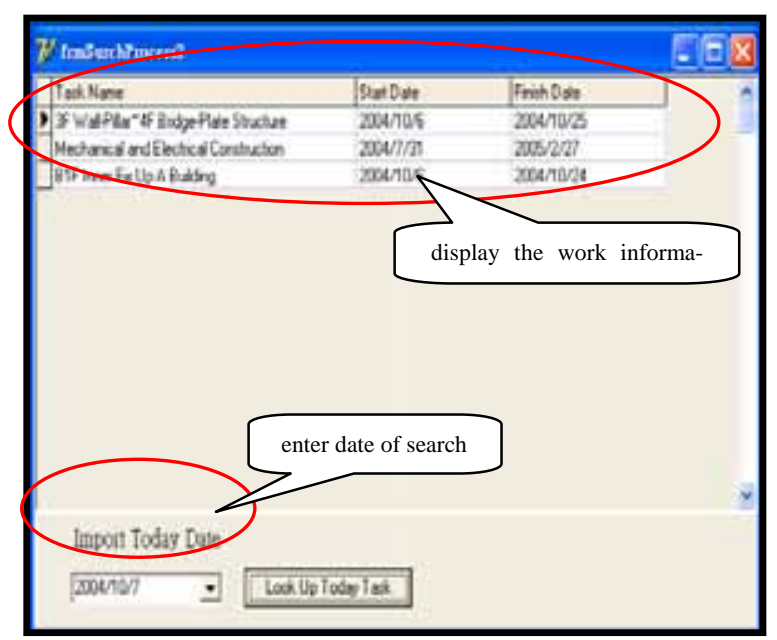

Fig 13 Search for information of schedule

Entering the date to be searched could display the work item on the present day (Fig 13) and content of completed work item (Fig 14), which allowed engineers to search conveniently and control the project schedule.

From entry and transfer of schedule control system in this research, as well as transformation of database via MS Access, relevant data of schedule control system was transformed into MS Project style and it could automatically renew the network of project. (Fig 15, 16) 


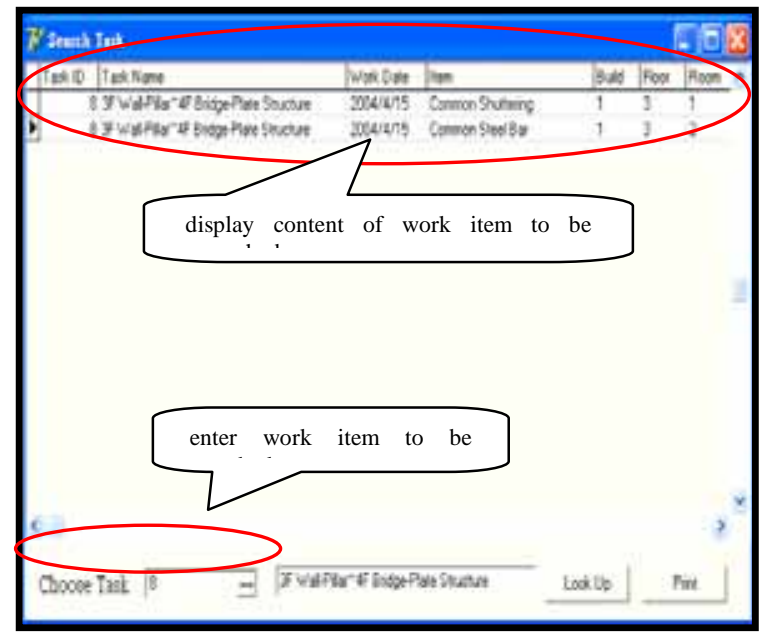

Fig 14 Search on content of work items

\section{CONCLUSION AND SUGgestion}

\section{A. Conclusion}

During depression of construction industry, it was more important to enhance the self competitiveness. The CMIS developed from this research did not only reduce the manpower and time wastage, but also accurately displayed the project schedule, which was expected to induce a certain level of contribution to the construction industry.

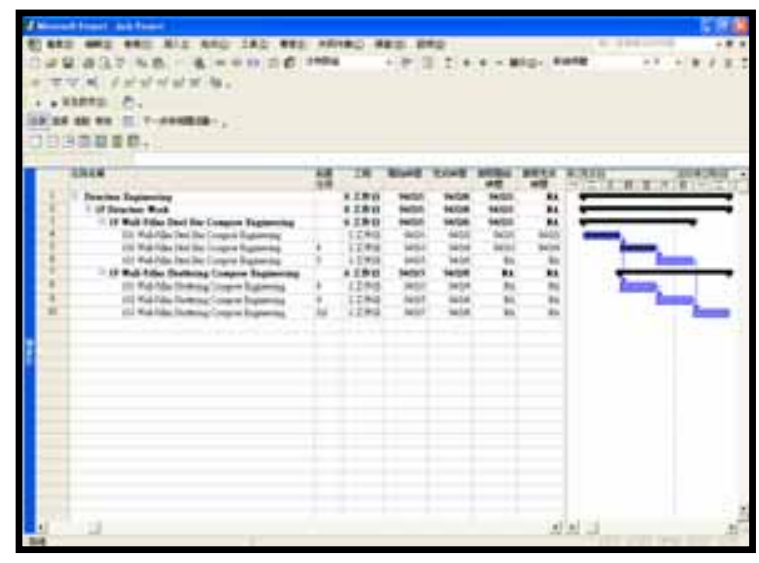

Fig 15 Original network of schedule in MS Project

The practical results of this research were as follows:

1). From investigation of this research, the relationships between MS Project and MS Access was understood, which allowed the data of CMIS schedule to be successfully transformed into MS Project for automatic renewal of network.

2). The function of daily site report system was expanded smoothly, which could not only clearly recorded items and quantities worked daily, but also automatically transferred accumulated monetary amount of items worked in each operation into the schedule control system.

3). Whether if it was the actual starting time, monetary amount of work, percentage of completion and actual finishing time, the schedule control system developed in this research could automatically calculate them all and display accordingly.

4). The schedule system was equipped with a search function, thus when the date to be searched was entered, it could display work items on the present day or the day before the present day, as well as information of the preset schedule and content of completed work items, which allowed engineers to search conveniently and control the project schedule.

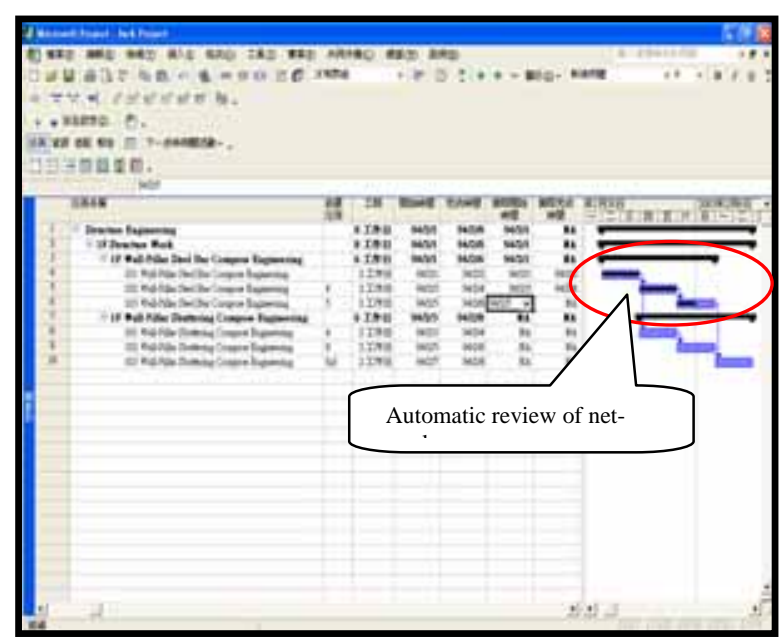

Fig 16 Transfer of system to MS Project for automatic renewal of network.

\section{B Suggestion}

Consequent research in the future suggested by this research included:

1). Integration of all site information for development of financial costing system, which could manage \& control project income and expense to increase profit for construction factory.

2). Consideration on loading information of daily site report into 3D motion picture to show schedule of completed work.

\section{ACKNOWLEDGEMENT}

I would like to take this opportunity to show my appreciation to National Science Council, Executive Yuan, for its support of the study. Project No.: NSC 92-2622-E-216-024-CC3.

\section{REFERENCE}

[1] Ruishiang Chiang, "Brief Discussion on Control of Project Assessment \& Costing”, Building the World, P. 17-24, September 2001.

[2] Wangjing Yang, "Study of object-orientated technology on control \& application of project cost - taking assessment \& costing as example", thesis for Master of Civil Engineering, National Taiwan University, 1998.

[3] Wenchian Wang, "Study on integrating system - assessment \& costing system for construction information”, thesis for Master, Institute of Construction Management, Chung Hua University (2002). 
[4] Fushun Liu, "Progress Planning and Controlling for Practical Construction”, Chan's Books Co., Ltd. September 1990.

[5] Shengfa Yang, "Study on compiling structure for information of construction site", thesis for Master of civil engineering, National Central University, 1995.

[6] Boing Lin, "Study on automated operation procedures of information management for construction site", thesis for Master of Civil Engineering, National Central University, 1996.

[7] Jingjeng Chiu, "Study of current status for information management on project progress", thesis for Master of civil engineering, Chung Hua University, 1994.

[8] Chaohe Chen, "Regulation of schedules", thesis for civil engineering, National Cheng Kung University, 1999.

[9] Jiecheng Huang, "Methodology of integration on schedule management system", thesis for civil engineering, National Cheng Kung University, 1999.

[10]Sulin Fan, "Study of applying object-orientated technology on project schedule calculation - taking interior finish work as example", thesis for civil engineering, National Taiwan University, 1995.

[11] Chonghao Wu, "Managing environment for research program schedule control and managing the sub-system", thesis for civil engineering, Tamkan University, 1995.

[12] Yichao Chou, "Application of E-R MODEL on system analysis", Computer and Communication No. 15, P. 35-41, March 1993.

[13] Dengtsi Chu, "Construction management - practical integration of costing, daily report, progress and cost control”, Seminar for digital construction - electronic information technology for construction industry, December 2002.

[14]Guangyi Feng, "Sharing experience for computerization of construction factory”, Thesis collection for seminar of sharing experience for automation of construction, March 1999.

[15]Yenchuan Hsiao, "Information record and search system of construction site”, Quarter issue of construction management No. 28, P. 26-43, September 1996.

[16]Jiajhen Chang, "Computerized structure for project management of construction factory - taking progress management as example", Building the world, No. 29, P. 32-37, May 1998.

[17]Fushun Liu and Wenyao Tsai, "Defects and corresponding strategy of management for project progress", Building the world, No. 92, P. 30-35, August 2003.

[18]Jiajhen Chang, "Discussion on computerization of management for work progress in construction factory", Building the world No. 22, P. 29-36, October 1997.

[19]Wenkai Tsai, "Discussion on delay of project progress”, Building the world No. 80, P. 7-9, August 2002.

[20]Lishing Yi, "Current state of introducing electronic construction industry - taking Ruentex Group as example”, Seminar of prompt practice for introducing electronic construction industry, 2002.

[21]Weijhen Yang and Yize Chen, “Analysis on object-orientated system”, Magazine of communication and education, P. 25-35, October 1993.

[22]Guojhen Liao, "Construction management and application of computer software”, Chinese technology no. 36, P 3-13. 